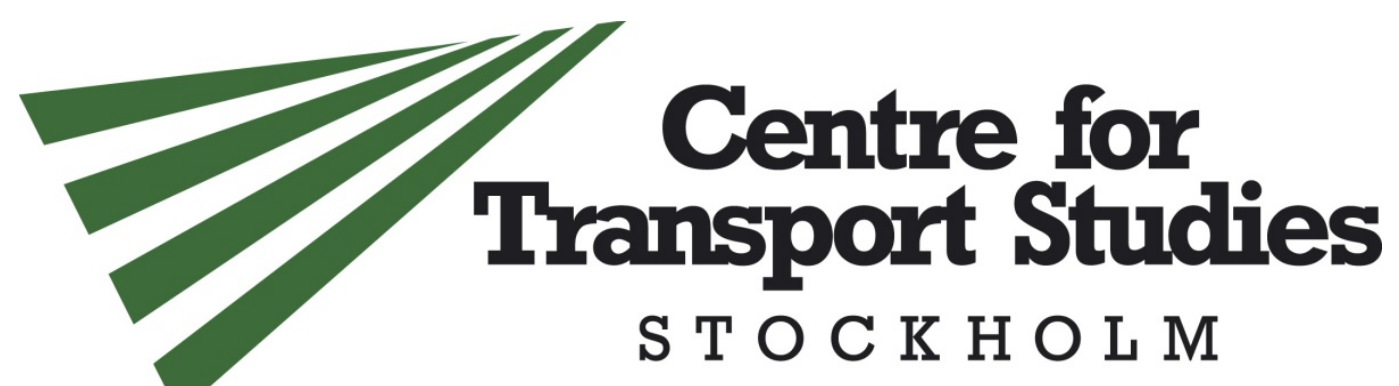

\title{
Why experience changes attitudes to congestion pricing: the case of Gothenburg.
}

\author{
Maria Börjesson, Jonas Eliasson, Carl Hamilton \\ Centre for Transport Studies, KTH Royal Institute of Technology
}

CTS Working Paper 2014: 14

\begin{abstract}
Many cities have seen public support for congestion charges increase substantially after charges have been introduced. Several alternative explanations of this phenomenon have been suggested, but so far little evidence has been available to assess the relative importance of these explanations. We study attitudes to congestion pricing in Gothenburg before and after congestion charges were introduced in January 2013. Attitudes to the charges did indeed become more positive after the introduction, just as in previous cities. Using a two-wave postal survey, we are able to separate contributions to the attitude change from a number of sources: benefits and costs being different than anticipated, use of hypothecated revenues, reframing processes, and changes in related attitudes such as attitudes to environment, equity, taxation and pricing measures in general. We conclude that the dominant reason for the attitude change is status quo bias, rather than any substantial changes in beliefs or related attitudes, although some of these factors also contribute to some extent. Contrary to a common belief, nothing of the attitude change is due to benefits being larger than anticipated.
\end{abstract}

Keywords: Congestion pricing, acceptability, attitudes, Gothenburg.

JEL Codes: H23, H54, R41, R48. 


\section{INTRODUCTION}

The main obstacle for introducing congestion pricing is often public resistance. However, several cities have reported that public support for congestion pricing has increased substantially after a congestion pricing system has been introduced (e.g. London (Schade \& Baum, 2007), Stockholm (Eliasson \& Jonsson, 2011; Eliasson, 2014); Trondheim, Bergen and Oslo in Norway (Tretvik, 2003); United States (Zmud (2008) quoted in Anas and Lindsey (2011)); Milan (Ozer, Beria, \& Pacchi, 2012); there is also some evidence for the phenomenon Singapore (Gopinath Menon \& Kian-Keong, 2004)). Several explanations for this phenomenon have been hypothesized, but so far there has been little conclusive evidence as to which of the potential explanations are the most important. The suggested explanations are not mutually exclusive, so in principle they may all contribute to some extent. The purpose of this paper is to determine their relative importance in a specific case, namely the introduction of congestion pricing in January 2013 in Gothenburg, Sweden's second largest city. Just as in the cases cited above, public attitudes in Gothenburg did indeed become substantially more positive after the introduction. Our central question is what has caused this change.

Based on an extensive before/after survey of public attitudes, we estimate models where respondents' attitudes to congestion charges are explained by factors such as expected toll payments, value of time, socioeconomic factors, beliefs about effects, and attitudes to related issues such as environment, equity, taxation, government and pricing policies in general. By comparing models and factors before and after the introduction, the contribution of various factors to the change in attitudes can be determined. As a side result, we can also identify which groups have changed their attitudes. To our knowledge, this is the first survey of its kind.

In the public debate, the most common explanation to the increased public support after introduction is that benefits turn out to be larger than anticipated. But several other mechanisms have been hypothesized, such as hypothecation of revenues, changes in related attitudes, reframing, and various forms of status quo bias. We test seven hypotheses that may explain the increased public support, which have all been suggested either in the public debate or in the scientific literature:

(1) Larger benefits than expected. The support for charges after introduction may increase because benefits such as reduced congestion and improved urban environment turn out to be larger than expected. This is by far the most common explanation, put forward e.g. in a prescient paper by Goodwin (2006).

(2) Smaller downsides than expected. Several authors have pointed out that adverse effects tend to be exaggerated before the introduction, and that resistance may decrease after introduction if problems such as increased transit crowding and decreased inner-city retail turn out to be less serious than anticipated. In addition, adapting to the charges may seem more costly beforehand than it actually turns out to be (Eliasson, 2008; Henriksson, 2009).

(3) Benefits of accompanying measures. Introduction of congestion charges is often accompanied by improvements in the transport system, for example in alternative modes or routes. These improvements are often paid for by (hypothecated) charge revenues, or at least marketed as part of a charges/infrastructure package. An increased satisfaction with e.g. the public transport system might spill over to an increased support for the charges. Several authors have argued that a "package approach" with accompanying measures is key for achieving acceptance for congestion pricing (Gopinath Menon \& Kian-Keong, 2004; Jones, 1991). 
(4) Changes in related attitudes. Attitudes to congestion charges tend to be influenced by other related attitudes and values, such as environmental concerns, concerns for social equity, trust in government, and acceptability of general pricing principles such as user pricing, polluter pricing and scarcity pricing (Eliasson \& Jonsson, 2011; Frey, 2003; Hamilton, Eliasson, Brundell-Freij, Raux, \& Souche, 2014; Raux \& Souche, 2004). The debates and campaigns surrounding the introduction of congestion charges may affect these other attitudes, which may then influence the attitude to congestion charges as a second-order effect. For example, it has been suggested that part of the increased support in Stockholm was caused by an increased acceptance for pricing policies in general (Börjesson, Eliasson, Hugosson, \& Brundell-Freij, 2012).

(5) Reframing. The strength with which various attitudes and values are associated with, and hence influence, the attitude to congestion charges may change over time, in particular if congestion charges are reframed, i.e. interpreted or marketed in a different way. For example, if congestion pricing is reframed from a fiscal policy to an environmental policy, it would be expected that the influence of selfinterest and attitudes to taxation becomes relatively weaker compared to the influence of environmental concerns. How policies are framed often has a crucial effect on public support; Heberlein (2012) provides several examples.

(6) Loss aversion. It is well established that losses are valued proportionally higher than gains in situations where there is a clear point of reference (Kahneman, 2011). Hence, one might expect that increases in travel costs are valued higher before congestion pricing is introduced than afterwards, and improved travel times are valued higher after the introduction than before. Both phenomena would imply that car drivers would become more positive after the introduction than before. Note that this is different from benefits being larger (1) or adverse effects smaller (2) than expected; loss aversion refers to the phenomenon when effects are valued differently after a change, even when their objective size is undisputed.

(7) Status quo bias. Status quo bias refers to situations when preferences for a policy are asymmetric - lower beforehand than afterwards. It may be caused by loss aversion, but can also be caused by cognitive dissonance (resistance tends to decrease if a change seems inescapable beforehand or irreversible afterwards) or resistance to changes as such, regardless of tangible losses or gains. Status quo bias of various kinds have been suggested to be one contributing factor to the increased support once congestion pricing is introduced (Brundell-Freij, Jonsson, \& Källström, 2009; Eliasson, 2014) or seems inevitable (Schade \& Baum, 2007).

In summary, we show that status quo bias (7) is the main contributing factor to the increased support in Gothenburg, with minor contributions from mechanisms (2)-(4). Contrary to what is often assumed, "larger benefits than expected" (1) does not play any role for the change in support. In fact, beliefs in positive effects decreased after the introduction, but support for the charges increased in spite of this.

The paper is structured as follows. Section 2 summarises the background and introduction of the Gothenburg congestion charges, and section 3 the data collection. Section 4 describes changes in attitudes and beliefs after the introduction compared to immediately before. Section 5 describes the factor analysis where fundamental attitude factors are constructed. Section 6 presents models estimating the influence of various variables on the attitude to the charges. Using these models, we are able to determine the contribution of the various explanations (1)-(7) to the change in attitudes. Section 7 concludes. 


\section{THE GOTHENBURG CONGESTION CHARGES}

The Gothenburg congestion charges have two purposes: revenue generation and congestion reduction. The background is that Stockholm, the capital of Sweden and the largest city in the country, introduced congestion charges in 2006. This decision was initially met with fierce public resistance, but public opinion started to shift in favour of the congestion charges soon after the introduction. In a referendum nine months after the introduction, a majority voted in favour of keeping the charges. After the referendum, the national government struck a deal with Stockholm that revenues from the congestion charges would be used to co-finance a major infrastructure package, where the charge revenue was leveraged with national funding. This was a paradigm shift in Swedish infrastructure funding; normally, investments in the national road and rail systems are funded by national grants.

The way in which Stockholm used revenues from congestion charges to, as it appeared, unlock substantial national funding served as a direct inspiration for Gothenburg politicians. Soon they were negotiating a similar package with the national government, where the plan was to introduce congestion pricing in Gothenburg and leverage the revenues with national funding to fund a large infrastructure package. Half of the package would be financed with national funds and half with regional funds, of which the majority would come from future congestion pricing revenues (a minor part was to be financed directly from the regional municipal budgets, which are funded by income taxation). The agreement was presented in 2009, preceded by virtually no public debate. All political parties in Gothenburg were in favour of the agreement. However, there was considerable public opposition, in particular against the congestion charges, which among other things led to the formation of a new political party campaigning against the charges ("Vägvalet", a pun roughly meaning "crossroads" or "choose the road").

The Gothenburg congestion charges hence have the dual purpose to generate revenues for the infrastructure package and reduce road congestion. The deal prescribed that the system had to generate around 1 billion SEK per year, a third more than the Stockholm revenues despite Gothenburg being less than half the size of Stockholm. The secondary design objective was to achieve as efficient congestion reduction as possible, given the revenue constraint. However, Gothenburg did not have a lot of road congestion; congestion was limited to a few junctions and the morning rush hour.

The scheme consists of a cordon with two additional tolling borders sprouting out from the cordon (Figure 1). Charges are levied 6:00-18:30 on weekdays, and range from 8 SEK to 18 SEK depending on the time of day. Vehicles are charged when they cross a toll border in any direction, but only have to pay one charge during any one-hour period. Preliminary results indicate that traffic across the toll cordon was reduced by $12 \%$, and that average congestion indices on the few congested links were reduced from $160 \%$ to $80 \%$ (although most affected links were not congested even before). 


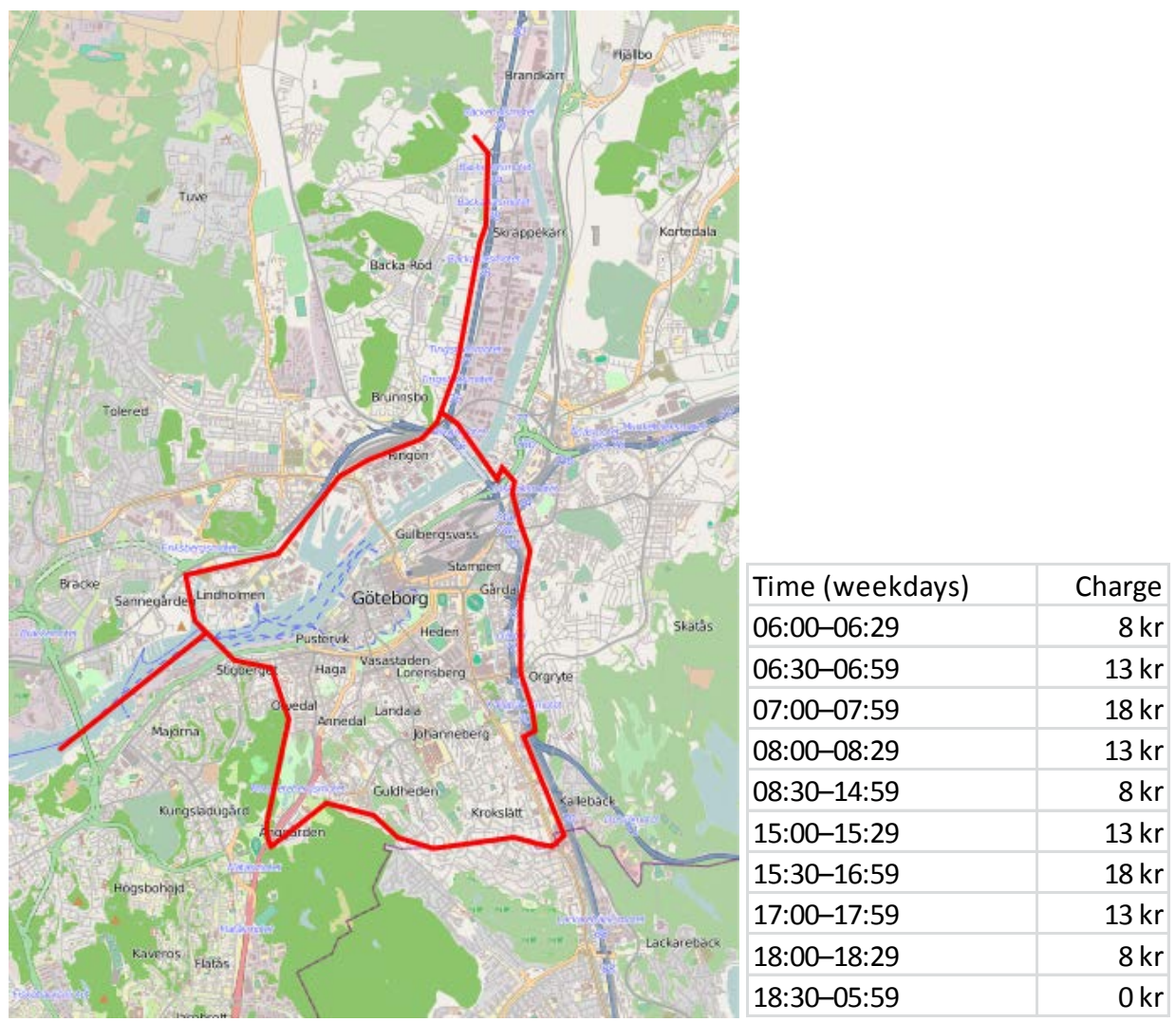

Figure 1. Gothenburg with toll borders in red, and charge levels per time period.

Almost immediately, opponents to the charges argued that there ought to be a referendum about the charges, just as in Stockholm. In the autumn of 2013, it was decided to hold such a referendum in the autumn of 2014.

\section{DATA COLLECTION}

The analysis in this paper is based on two postal surveys carried out in Gothenburg before and after the introduction of congestion charges in January 2013. The first wave took place in November 2012 and the second wave in November 2013. The survey is an adaptation of a survey first developed and used in a Swedish-French-Finnish study (Hamilton et al., 2014; Souche et al., 2014). The surveys were sent to random samples of adult residents in relatively central part of the Gothenburg region (the municipalities of Göteborg, Mölndal, Partille and Öckerö, and the postal areas Mölnlycke and Landvetter in Härryda municipality), resulting in around 1500 useable responses per year with response rates of $40 \%$ and $38 \%$, respectively. The samples are independent, i.e. this is not a panel study; disadvantages such as attrition, self-selection and anchoring were judged to be larger than potential advantages of a panel study.

Respondents were asked "In a referendum about the congestion charges and the related infrastructure package, how would you vote?" with answers on a five-grade scale from "Definitely yes" to "Definitely no". The question was about both the congestion charges and the infrastructure, since they are intimately linked to each other; without congestion pricing, the infrastructure package is unlikely, and the other way around. At the time of the first wave (November 2012), a referendum was discussed but no decision had been made. At the time of the second wave (November 2013), it had recently been decided to hold a referendum in September 2014. Hence, the question was not a hypothetical issue. 
The survey also contained questions about a range of other issues; in fact, the study was presented as a general survey related to traffic attitudes, not a focused congestion pricing study. Respondents were presented with statements such as "Taxes are too high" and "Much more resources should be spent on protecting the environment", and asked to what extent they agreed on a 7-grade scale, from "completely disagree" (1) over "neutral" (4) to "completely agree" (7)". Some of the statements concerned social and political issues that might be associated with congestion pricing, such as environment, taxation and social equity. Some of them concerned acceptability for pricing mechanisms in other contexts, such as differentiated air fares and taxing noise and emissions.

Respondents' support for congestion charges can be expected to be related to their value of travel time savings. As an indicator of the value of time, respondents were asked to imagine the following situation:

You commute daily by car. On the way, you have to cross a bridge across a river. One day the bridge closes for repairs for some time. Another bridge is available further downstream, but the detour takes an additional 20 minutes. During the time the bridge is repaired, the road authority has arranged a ferry that can take cars across the river. What is the highest amount you would be prepared to pay for a one-way ferry ticket, to save 20 minutes on your journey to work?

Such a question only gives a rough indication of respondents' actual valuation of travel time savings - its purpose is only to enable us to explore the relation between respondents' value of time and their support for congestion charging. However, the resulting value of time distribution turned out to be close to what real value of time studies have found (e.g. (Börjesson \& Eliasson, 2014)).

Respondents' attitude to congestion charges can also be expected to be related to perceived fairness of various possible allocation mechanisms. To measure this, the question continued:

Some people complain to the authority that it is unfair that the authority charges a price for the ferry tickets. When offering the ferry for free, it turns out that there is not room on the ferry for everyone who wants to use it. The authority now considers four different methods to choose who gets to travel with the ferry. To what extent do you consider these alternatives fair?

- Price: Revert to the original policy of charging those who want to travel, and set the price so the ferry is just filled.

- Queue: Those who arrive first to the jetty and stand first in line get to go with the ferry.

- Authority determines "need": Those who want to travel with the ferry have to show some evidence to support their need. The authority then provides ferry passes based on their judgment of the greatest need.

- Lottery: Tickets are allocated randomly, so that everybody has an equal chance of winning.

- Rationing: The number of ferry trips per person is limited to three trips per week.

Respondents were asked to rate the fairness of each allocation mechanism on a 7-grade scale, from "Completely unfair" to "Completely fair". 


\section{CHANGES IN ATTITUDES AND BELIEFS}

The National Transport Administration has carried out repeated surveys of Gothenburg attitudes to the congestion charges and the infrastructure package. That survey is not directly comparable with ours for two reasons. First, the Transport Administration's survey covers the whole Gothenburg region, whereas our survey only includes the city of Gothenburg; second, the Transport Administration's survey asks about the opinion about the congestion charges only, whereas our survey asks about the opinion about the package of charges and infrastructure investment. Both of these differences mean that public support becomes lower in the Transport Administration's survey; the difference is around 10 percentage points. Results are shown in Figure 2. For our purposes in this paper, the important point is that the change over time in the two surveys is similar.

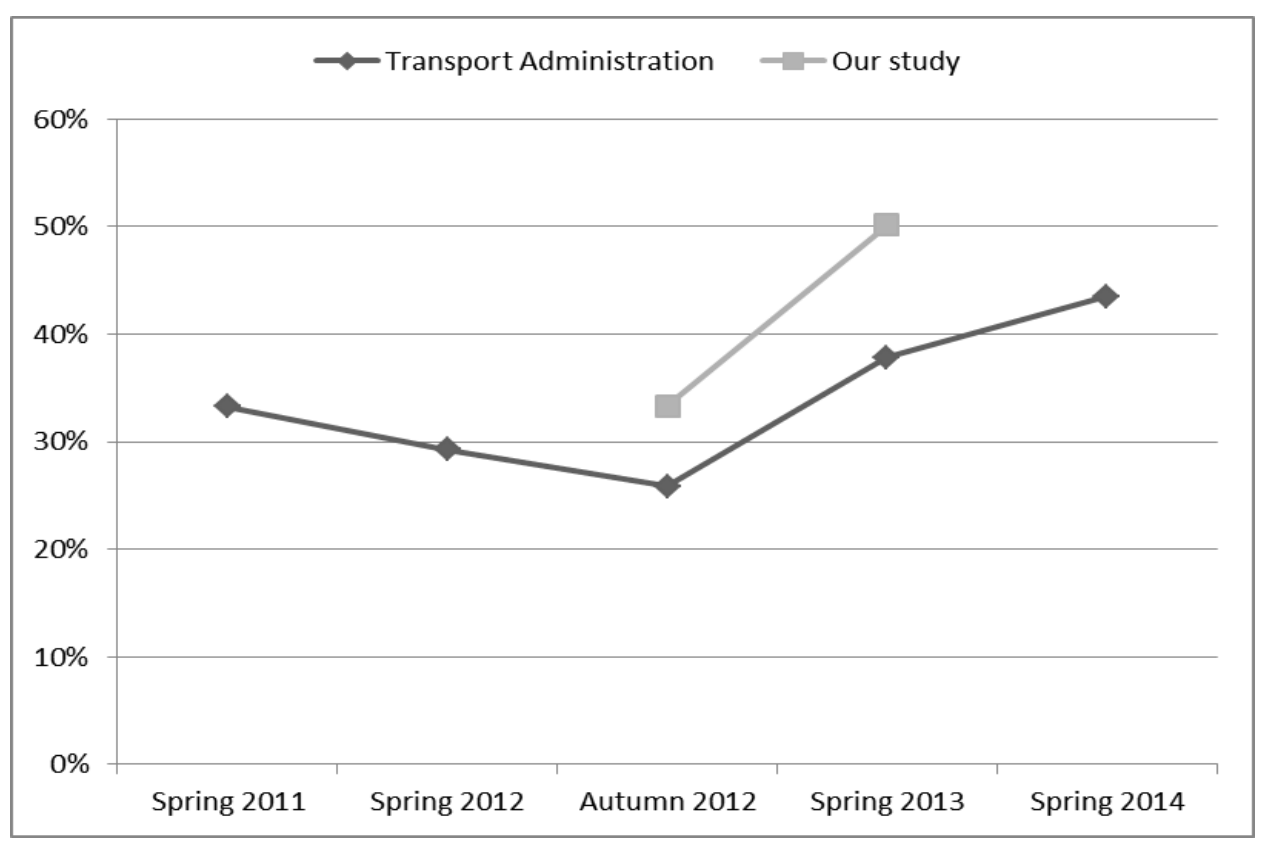

Figure 2. Public support for the congestion pricing/infrastructure package; share of respondents who state that they would vote in favour of the package in a referendum, excluding "don't know/wouldn't vote" responses. Note that congestion charges were introduced in January 2013.

In our before/after survey, respondents were asked how they would vote in a referendum about the congestion charges and the associated infrastructure package ${ }^{1}$. Results are presented in Table 1.

Table 1. Stated voting in a referendum about the congestion charges and the infrastructure package.

\begin{tabular}{|c|c|c|c|c|c||c|}
\hline & $\begin{array}{c}\text { Definitely } \\
\text { yes }\end{array}$ & $\begin{array}{c}\text { Probably } \\
\text { yes }\end{array}$ & $\begin{array}{c}\text { Don't } \\
\text { know }\end{array}$ & $\begin{array}{c}\text { Probably } \\
\text { no }\end{array}$ & $\begin{array}{c}\text { Definitely } \\
\text { no }\end{array}$ & $\begin{array}{c}\text { Support excl. } \\
\text { "Don't know" }\end{array}$ \\
\hline $\mathbf{2 0 1 2}$ & $10 \%$ & $19 \%$ & $14 \%$ & $24 \%$ & $34 \%$ & $33 \%$ \\
\hline $\mathbf{2 0 1 3}$ & $19 \%$ & $23 \%$ & $16 \%$ & $20 \%$ & $22 \%$ & $50 \%$ \\
\hline change & $+9 \%$ & $+4 \%$ & $+2 \%$ & $-4 \%$ & $-12 \%$ & $+17 \%$ \\
\hline
\end{tabular}

\footnotetext{
${ }^{1}$ Note that the question deals with the congestion charges and the infrastructure package as a whole. However, it seems that the charging system is the truly divisive issue. The survey also asked respondents whether they would become more positive or negative if the infrastructure package was funded by increased municipal income tax instead. Around half of the no-voters would then become more positive.
} 
Almost a year after the introduction, public opinion had become much more positive. Excluding "don't know", the share of positive respondents had increased from 33\% to $50 \%$. Moreover, the positive respondents were more convinced while the negative respondents were less convinced on average: the share of yes-voters that would "definitely" vote yes had increase from a third to a half, while the share of no-voters that would "definitely" vote no had decreased from three fifths to half.

Gothenburg is hence yet another city where public opinion has become more positive after the introduction of congestion charges. The development of attitudes follows the general pattern described already in Goodwin (2006), reproduced in Figure 3. Drawing on "many separate research projects, experience in Edinburgh, London and many other places", Goodwin argues that public opinion follows a certain trajectory. At first, the general idea gets decent support, but when the "devil of the detail emerges", support falls. When the system starts, however, and the "promises of improvement are actually, more or less, delivered", there is a "building up of support, perhaps over many years". The attitude development in Stockholm also followed the same pattern (Eliasson, 2014).

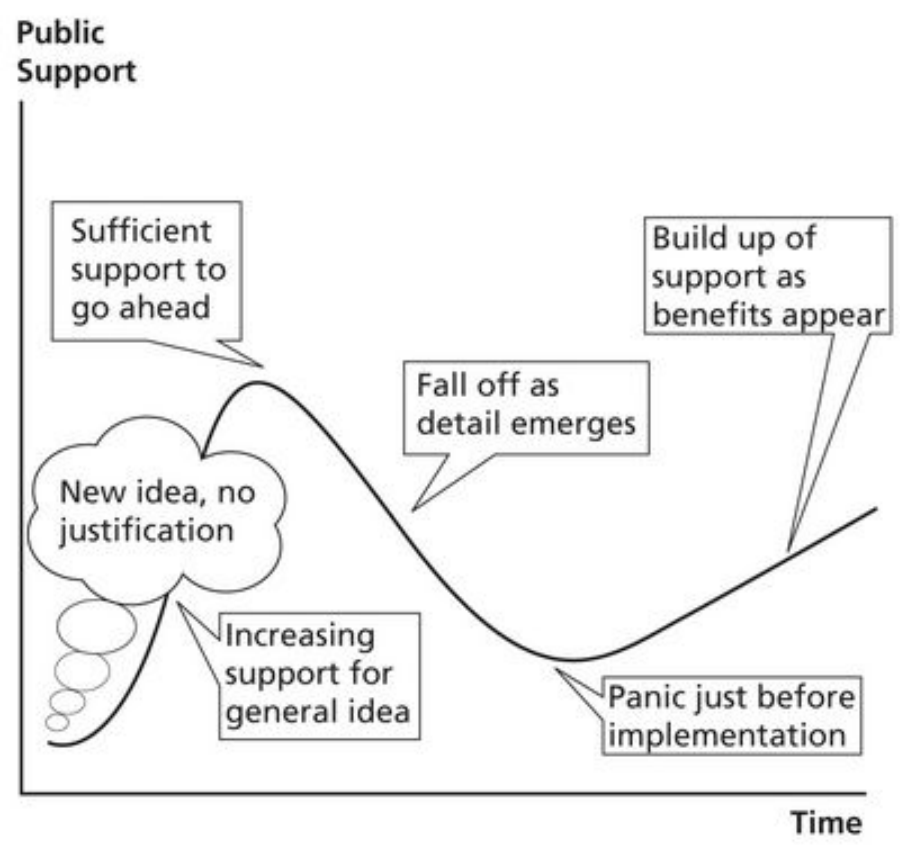

Figure 3. "The gestation process for road pricing schemes", reproduced from Goodwin (2006).

Goodwin hence hypothesizes that the increase in support can be attributed to the benefits that appear in the form of traffic and congestion reductions. This is hypothesis (1) in the introduction, and seems to be the most common explanation for the change in opinion among commentators. Several studies have also found strong links between support for congestion charges and belief in their effectiveness (see e.g. Eliasson and Jonsson (2011)). Although these studies have studied cross-sectional connections between attitudes and beliefs, rather than changes over time, the hypothesis obviously seems natural.

In the next section, we test this explanation and its sibling "adverse effects turn out to be less severe than expected" (hypotheses (1)-(2) in the introduction) by exploring how beliefs about effects changed after the introduction. Another way to explain the attitude change is to assume that attitudes to related issues change, or that the links from such related issues to the congestion pricing issue change (e.g. due to reframing). 
Section 6.2 hence explores the changes in related attitudes, and the changes in their correlation with the attitude to congestion pricing.

\subsection{Beliefs about effects}

In the surveys, respondents were asked about their beliefs regarding the effects of the charges, before and after the introduction. The survey presented a number of variables, such as congestion and transit crowding, and asked respondents how they thought the charges would influence (or had influenced, after the introduction) these variables, on a 7-grade scale from "Large decrease" to "Large increase". Results are presented in Table 2 , showing the share of respondents that believed that charges would affect/had affected the variable in the expected way.

Table 2. Beliefs in effects of the charges, before and after the introduction.

\begin{tabular}{|l|r|r|}
\hline & $\begin{array}{r}\text { Agree } \\
\mathbf{2 0 1 2}\end{array}$ & $\begin{array}{r}\text { Agree } \\
\mathbf{2 0 1 3}\end{array}$ \\
\hline $\begin{array}{l}\text { The number of car trips to and from central Gothenburg will } \\
\text { decrease/has decreased }\end{array}$ & $61 \%$ & $53 \%$ \\
\hline Time spent in car queues will decrease/has decreased & $47 \%$ & $45 \%$ \\
\hline Crowding in public transport will increase/has decreased $^{2}$ & $79 \%$ & $61 \%$ \\
\hline Retail within the cordon will decrease/has decreased $^{3}$ & $54 \%$ & $42 \%$ \\
\hline The quality of life for residents within the cordon will/has... & $41 \%$ & $37 \%$ \\
$\ldots$ increase(d) & $17 \%$ & $18 \%$ \\
\hline ...
\end{tabular}

Before the introduction, $61 \%$ believed that car trips to and from the city centre would decrease, although only $47 \%$ thought that this would lead to less car queues. After the introduction, the number of people believing that car trips had decreased actually decreased compared to before the introduction; on the other hand, the number believing in congestion reductions remained roughly the same. Turning to less tangible effects, $41 \%$ believed that the general quality of life would improve for residents within the cordon, while $17 \%$ believed that it would deteriorate. After the introduction, slightly fewer believed in increased quality of life, while the number believing in deterioration remained the same. In summary, the share of respondents believing in positive effects did not increase, refuting hypothesis (1); in fact, the belief in positive effects actually decreased somewhat.

However, the share of respondents believing in negative effects decreased compared to before the introduction. The share of people believing in increased transit crowding sank from $79 \%$ to $61 \%$, while the share believing in negative retail effects decreased from $54 \%$ to $42 \%$. This lends some support to hypothesis (2).

Clearly, expressing beliefs in positive or negative effects can to some extent be a way to rationalize one's attitude towards congestion charges. For example, self-interest may cause a negative attitude to congestion charges among car drivers, and these may then rationalize this attitude by expressing disbelief in positive effects. Similarly, respondents who are negative to car traffic for environmental reasons may be positive to increasing the cost of driving, and may partly rationalize this through expressing belief in many sorts of positive effects. This is a well-established psychological mechanism in many contexts; we will show two indications that it is at work in our study as well.

\footnotetext{
${ }^{2}$ Around 5\% thought that transit crowding would decrease/had decreased.

${ }^{3}$ Around $12 \%$ thought that retail in the charged areas would increase.
} 
First, Figure 4 suggests that self-interest influence beliefs. The more car trips respondents make, the more they believe that congestion charges will affect inner-city retail negatively, and the less they believe that congestion will be reduced. (The y-axis is the average response on a 4-grade scale from "No effect" (0) to "Large decrease" (3).) Note that beliefs in the negative effect, reduced retail, decrease from 2012 to 2013 across all groups, while beliefs in the positive effect, reduced congestion, remain stable.

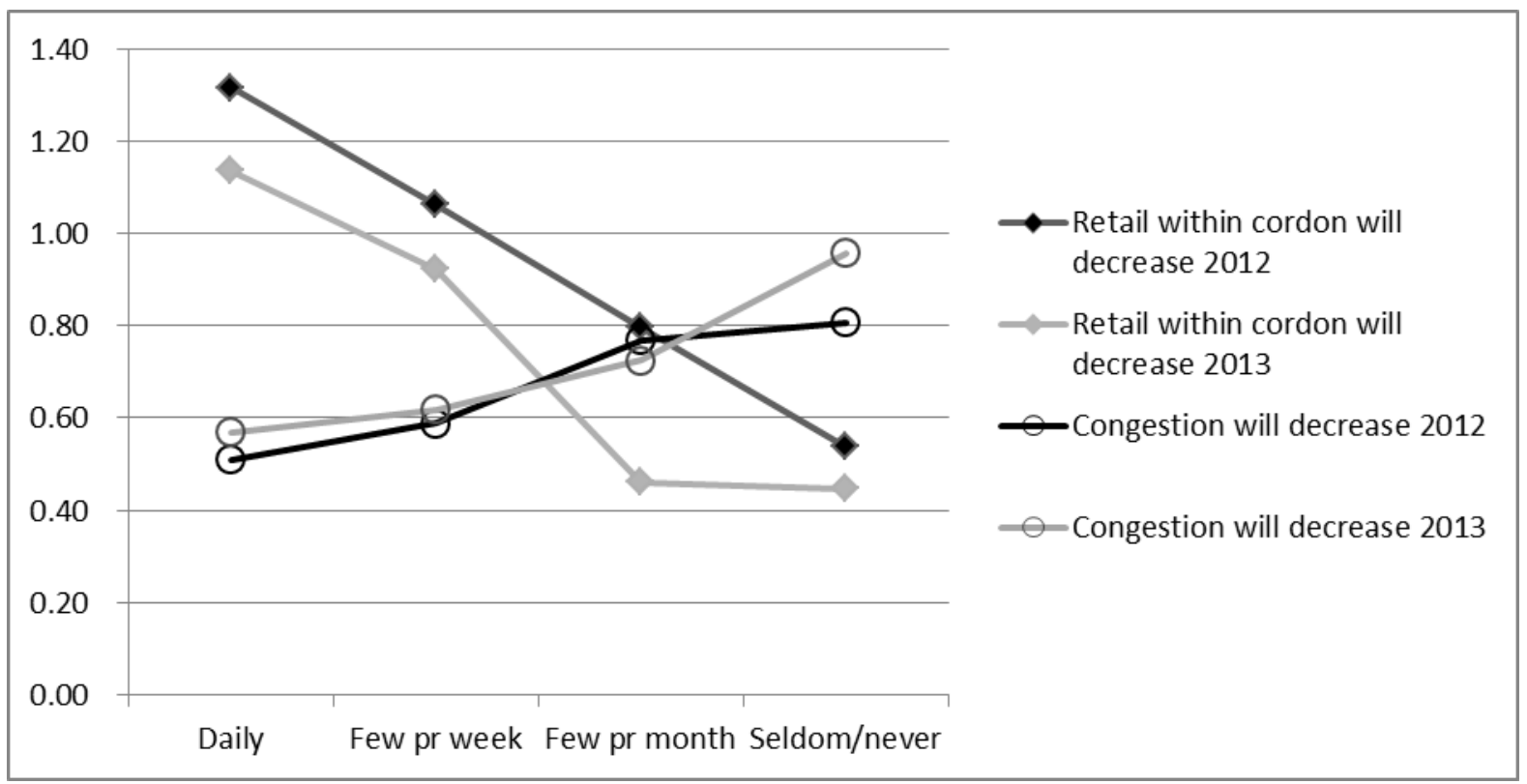

Figure 4. Self-interest influences beliefs: Beliefs in effects of the charges, with respect to how often respondents drive across the cordon.

Second, Figure 5 suggests that attitudes also influence beliefs. The stronger environmental concerns respondents have, the more they believe in positive effects on congestion reduction and the less they believe in negative effects for inner-city retail. Since environmental concerns are strongly correlated with positive attitudes to congestion charges (which will be shown below, confirming several other studies), this suggests that respondents who are positive to congestion charges for environmental reasons are more prone to believe in other kinds of positive effects as well, and less prone to believe in downsides. Again, it is worth noting that beliefs in the negative effect decrease from 2012 to 2013 across all groups, while beliefs in the positive effect remain stable. 


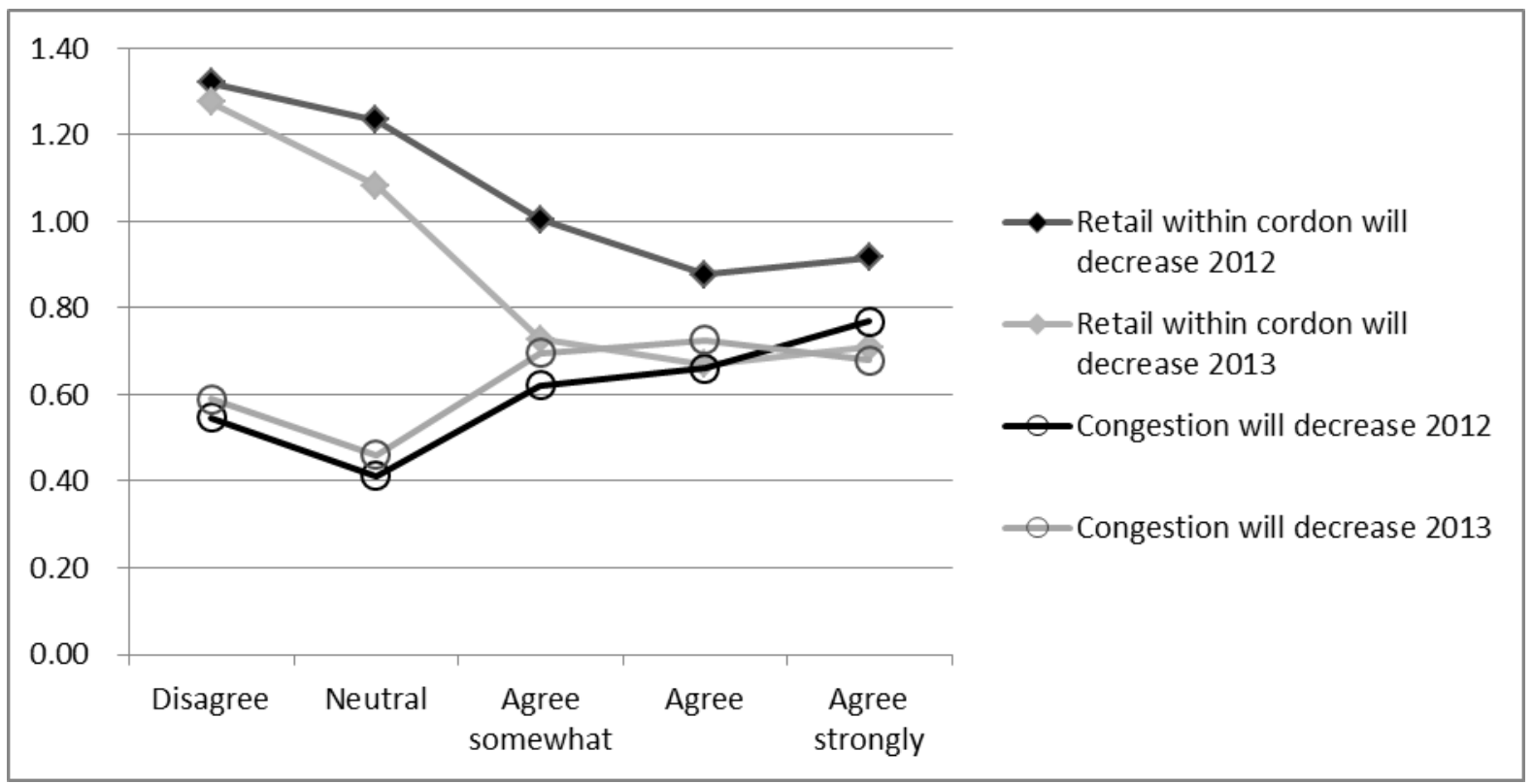

Figure 5. Attitudes influence beliefs: Belief in effects of the charges, with respect to how respondents agree with "Much more resources should be spent on protecting the environment".

From the above, it would seem that beliefs are more strongly influenced by attitudes and self-interest the less direct experience respondents have. Few if any respondents have first-hand information of effects on inner-city retail, and no studies of such effects were published. Beliefs hence have to be founded on hearsay and gut feeling, which likely makes them more prone be influenced by attitudes - one believes what one hopes to be true, essentially. Congestion, on the other hand, is visible to the naked eye, and many have direct experience, or have neighbours or friends who have. This likely reduces the influence from attitudes on beliefs. The influence from attitudes and selfinterest on beliefs about transit crowding (not shown here) is even smaller. This is consistent with many results in social psychology (see Heberlein (2012) for a summary and discussion).

\subsection{Attitudes to related issues}

The surveys measured attitudes to a number of issues, hypothesized to be related to the attitude to congestion charge, by presenting respondents with statements and asking whether they agreed or disagreed on a 7-grade scale from "completely disagree" (1) over "neutral" (4) to "completely agree" (7)". Results for the two years are presented in Table 3, showing the mean response on the 7-grade scale. The table also shows the correlations with respondents' voting intention in the congestion charging referendum. Positive correlations indicate that agreeing with the statements is correlated with being positive to congestion charges, and vice versa. Finally, the table shows the responses to the "ferry question" (see section 3), where different ways to allocate scarce space on a ferry were rated with respect to fairness. 
Table 3. Attitudes before and after the introduction, and correlation with voting in a referendum about the charges. $(*=$ significant change between the years)

\begin{tabular}{|c|c|c|c|c|}
\hline $\begin{array}{l}\text { Attitude } \\
\text { (1=completely disagree, } 4=\text { neutral, } 7=\text { disagree) }\end{array}$ & $\begin{array}{l}\text { Mean } \\
2012\end{array}$ & $\begin{array}{l}\text { Mean } \\
2013\end{array}$ & $\begin{array}{l}\text { Corr. } \\
2012\end{array}$ & $\begin{array}{l}\text { Corr. } \\
2013\end{array}$ \\
\hline $\begin{array}{l}\text { "Motor traffic is among the largest threats to the } \\
\text { environment." }\end{array}$ & 4.5 & 4.5 & 0.42 & 0.37 \\
\hline $\begin{array}{l}\text { "It would be reasonable if the noisiest cars and } \\
\text { motorcycles were subject to a special noise tax" }\end{array}$ & 3.7 & 3.8 & 0.26 & 0.30 \\
\hline $\begin{array}{l}\text { "Considerably more resources should be used to } \\
\text { protect the environment." }\end{array}$ & 5.3 & 5.4 & 0.28 & 0.29 \\
\hline $\begin{array}{l}\text { "It is reasonable that airplane tickets cost more for } \\
\text { departure during peak hours than during off-peak" }\end{array}$ & 4.5 & 4.6 & 0.21 & 0.23 \\
\hline $\begin{array}{l}\text { "Road congestion is one of Gothenburg's largest } \\
\text { problems" }\end{array}$ & 5.0 & 4.9 & 0.24 & 0.19 \\
\hline $\begin{array}{l}\text { "I am satisfied with the public transport in } \\
\text { Gothenburg." }\end{array}$ & 3.5 & $4.0^{*}$ & 0.22 & 0.17 \\
\hline $\begin{array}{l}\text { "The government should prioritise to reduce } \\
\text { differences between low- and high-income groups" }\end{array}$ & 5.3 & 5.5 & 0.12 & 0.13 \\
\hline $\begin{array}{l}\text { "It would be reasonable if transit fares were lower } \\
\text { outside peak hours" }\end{array}$ & 5.1 & 5.1 & -0.05 & -0.05 \\
\hline "Taxes are too high" & 4.5 & $4.2^{*}$ & -0.38 & -0.39 \\
\hline $\begin{array}{l}\text { "Charges and taxes to own, park and drive a car are } \\
\text { too high" }\end{array}$ & 4.9 & $4.7^{*}$ & -0.54 & -0.55 \\
\hline \multicolumn{5}{|l|}{$\begin{array}{l}\text { Fairness of ways to allocate space on the ferry: } \\
\text { (1=completely unfair; } 4=\text { neutral; } 7=\text { completely fair) }\end{array}$} \\
\hline Pricing & 5.1 & $5.3^{*}$ & 0.12 & 0.14 \\
\hline Queuing & 5.1 & 5.1 & -0.04 & -0.05 \\
\hline Government decision based on "need" & 3.5 & 3.6 & 0.12 & 0.18 \\
\hline Lottery & 2.0 & 2.0 & 0.09 & 0.20 \\
\hline Rationing & 3.7 & 3.7 & 0.13 & 0.11 \\
\hline
\end{tabular}

Most attitudes are stable across the years. Only four changes are significantly different, marked with $*$ in the table. In 2013, less respondents agree with the statements "charges and taxes to own, park and drive a car are too high" and "taxes are too high". In addition, more respondents regard pricing the ferry as "fair". From the correlation coefficients, we see that these attitude changes will tend to increase the support for the charges. This lends some support to hypothesis (4), although the effect seems small. It should be emphasized that these attitude changes are not necessarily caused by the introduction of the charges. Several opinion polls noted an increase in voting support for the left/green political block during the measurement period, and higher support for taxation and high driving costs is perfectly consistent with this general political trend. It may hence be that during this time period, there was a general political trend to the left, and this happened to work in favour of the charges.

However, using a price instrument to allocate a scarce reseource, such as ferry capacity, is not usually associated with the left/green ideological spectrum. Despite this, there has been a significant change in the number of respondents who view pricing the ferry as "fair". It seems plausible that this change may be due to the introduction of the charges, especially since no other of the ferry allocation attitudes change. As Frey (2003) points out, it is more common that publicly controlled resources are allocated through regulations or rationing than through pricing, and this may be one factor contributing to lack of acceptability for congestion charges. Once the public gets more used to the possibility, however, this factor may become less important. 
The fourth attitude change is that more respondents are satisfied with public transport. This is likely related to the extensive public transport improvements and marketing campaigns shortly before and after the introduction of the charges. This change will tend to increase the support for the charges, lending support to hypothesis (3).

Correlations between the surveyed attitudes and the attitude to the congestion charges are also generally stable. The link between attitude to congestion charges and viewing traffic as an environmental threat has become a little stronger; the same is true for viewing congestion as one of the biggest problems. Since these are statements a majority of respondents agree with, this change in how attitudes are linked to each other would tend to increase support for congestion charges. The effect is relatively small, however. That these correlations look stable casts some doubt on hypothesis (5) in the introduction, although more careful econometric analysis is necessary to assert this (see section 6).

\section{ATTITUDE FACTORS}

The surveys contained a large number of attitude questions, relating to attitudes to e.g. social equity, environmental issues, taxation, traffic problems, various kinds of pricing policies etc. Naturally, there are correlations between many of these attitudes - some obvious, others less so. We have used factor analysis to identify these correlations, and reduce the number of attitude questions down to a small number of attitude factors, which can be thought of as latent fundamental attitudes.

The factor analysis was performed using SPSS. The varimax rotation was applied and only variables with a factor loading of at least 0.4 were used in the interpretation. All the variables in Table 4 were included in the analysis. The number of eigenvalues greater than 1.0 determined the number of factors. The factors were determined through the variance shared with the other variables. Factor analysis is only justified as long as the factors are interpretable. The same factors were obtained in the 2012 and 2013 samples when estimated separately. The factors are hence stable across years. The factor indices for each individual are computed as the average of the responses to the questions included in each factor. The factor indices can be interpreted as observations of latent variables reflecting a fundamental value.

The factor analysis resulted in a rotated component matrix indicating four attitude factors, presented in Table 4. Each of the rows corresponds to a statement, to which respondents were asked whether they agreed or disagreed on a 7 -grade scale. ${ }^{4}$ The non-zero elements indicate which statements belonging to each factor. A positive number in a column sign indicates that agreeing with the statement contributes positively to the corresponding factor, and a negative number that disagreeing with the statement contributes positively. The first factor, Pricing Acceptance (PRICE), combines statements expressing that pricing is a fair or reasonable way to allocate scarce resources or regulate externalities. The second factor, Tax Resistance (TAX), combines statements expressing that both taxes and car levies are too high, and disagreeing with the notion that car traffic is a big environmental problem. The third factor, Equity Concerns (EQUI), combines concerns for equity and seeing governmental decisions as a fair allocation mechanism. The fourth factor, Environmental Concerns (ENV), combines environmental concerns, support for measures that can be interpreted as traffic restraints (speed cameras, pricing the car ferry) and concerns for equity.

\footnotetext{
${ }^{4}$ In a few questions, the formulation was slightly different, as explained previously in the paper. This is indicated by a lack of quotes around the statement.
} 
Table 4. Attitude factors and their components; Rotated factor loadings

\begin{tabular}{|c|c|c|c|c|}
\hline & PRICE & TAX & EQUI & ENV \\
\hline $\begin{array}{l}\text { "Considerably more resources should be used to protect the } \\
\text { environment." }\end{array}$ & & & & 0.646 \\
\hline $\begin{array}{l}\text { "Automatic speed cameras is a reasonable way to improve } \\
\text { traffic safety" }\end{array}$ & & & & 0.657 \\
\hline "Road congestion is one of Gothenburg's largest problems" & & & & 0.564 \\
\hline $\begin{array}{l}\text { "Motor traffic is among the largest threats to the } \\
\text { environment." }\end{array}$ & & -0.356 & & 0.669 \\
\hline $\begin{array}{l}\text { "Charges and taxes to own, park and drive a car are too } \\
\text { high" }\end{array}$ & & 0.821 & & \\
\hline "Taxes are too high" & & 0.878 & & \\
\hline $\begin{array}{l}\text { "It is reasonable that airplane tickets cost more for departure } \\
\text { during peak hours than during off-peak" }\end{array}$ & 0.777 & & & \\
\hline $\begin{array}{l}\text { "It is reasonable that charter operators raise their prices } \\
\text { when the Swedish weather is bad." }\end{array}$ & 0.785 & & & \\
\hline $\begin{array}{l}\text { "The government should prioritise reducing differences } \\
\text { between low- and high-income groups." }\end{array}$ & & & 0.468 & 0.465 \\
\hline Pricing the ferry is a fair allocation mechanism. & 0.392 & & & 0.468 \\
\hline $\begin{array}{l}\text { Letting a government agency decide who get to use the ferry } \\
\text { is a fair allocation mechanism. }\end{array}$ & & & 0.714 & \\
\hline $\begin{array}{l}\text { Would become more positive to congestion charges if the } \\
\text { charge was lower for low-income drivers }\end{array}$ & & & 0.716 & \\
\hline Average factor index 2012 & 4.05 & 4.87 & 4.13 & 5.12 \\
\hline Average factor index 2013 & 4.16 & 4.67 & 4.24 & 5.18 \\
\hline t-test for Equality of Means ${ }^{5}$ 2012-2013 & 1.78 & -3.42 & 2.43 & 1.35 \\
\hline
\end{tabular}

Each respondent has an index for each attitude factor, and these will be used in the subsequent estimation of determinants of attitudes to congestion pricing. The indices are computed as the average of the responses to the statements belonging to each factor (see IBM Corp. Released 2012. IBM SPSS Statistics for Windows, Version 21.0. Armonk, NY: IBM Corp.). The indices thus show to what extent the individuals agree with the statements included in each factor. The bottom rows of Table 4 show average factor indices for each year. They remain broadly unchanged, which is natural since very few of the underlying attitudes change significantly (see Table 3 ). There is, however, a significant tendency of declining tax resistance and increasing equity concerns, which is consistent with the general political trend in favour of the left/green political block noted above.

A regression of respondents' characteristics on the attitude factors (see appendix) show that high PRICE indices are correlated with high education, high wage, high value of time and low age; high TAX indices are correlated with high age, low transit and bicycling trip frequency, low education and low wage; high scores on EQUI with high age, high transit and bicycling trip frequency, low wage and high value of time; and high scores on ENV with high transit and bicycling trip frequency, low wage and high value of time.

\section{DETERMINANTS OF ATTITUDES TO CONGESTION PRICING}

We are now ready to attack the main question of the paper, namely what has caused the increased support for the congestion charges after their introduction. A number of

${ }^{5}$ Not assuming equal variance across the years. 
possible explanations were suggested in the introduction, which can all contribute to some extent. Let us repeat the hypotheses and summarize our findings so far:

(1) The benefits of the charges may have turned out to be larger than expected. However, we have already seen in section 4 that this is not the case. If anything, beliefs in positive effects are weaker than before the charges were introduced.

(2) The adverse effects of the charges may have turned out be smaller than expected. We have seen some signs of this in section 4, but mostly for effects that are not experienced directly by respondents and hence are more prone to be influenced by attitudes. Hence the causality may well be that the changes in beliefs are caused by the changes in attitudes to the charges, rather than the other way around.

(3) Shortly before the introduction of the charges, substantial improvements were made in the Gothenburg public transport system, such as several new express bus lines. Consequently, we showed in section 4 that satisfaction with public transport had increased. These improvements were part of the overall charge/infrastructure package and partly financed by the charge revenues, so an increased satisfaction with the public transport system might spill over to an increased support for the charges.

(4) The introduction of the charges and the surrounding debate may have influenced other attitudes that are related to acceptability for congestion pricing. Changes in such attitudes may then change the support for congestion charges, as a secondorder effect. For example, it has been suggested that part of the increased support in Stockholm was caused by an increased acceptance for pricing policies in general. We saw in section 4 that some of the attitude changes would tend to increase support for the charges. For example, pricing the ferry was rated as more fair, and fewer thought that taxes were too high or that driving costs were too high.

(5) The Gothenburg charges can be framed (i.e. "viewed" or "interpreted") as a revenue source, an environmental policy or a congestion reduction measure. Depending on how the charges are framed, the influence of other attitudes may be strengthened or weakened. Possibly, the intense public debate, media coverage and political campaigning may contribute to a reframing of the charges. However, the findings above indicate that this is not the case: correlations between the attitude to congestion charges and other attitudes have in fact remained stable.

(6) Loss aversion may be a factor; so far, we have not presented any evidence supporting or refuting this explanation

(7) The same holds for status quo bias.

To explore the hypotheses further, we estimate econometric models to measure how various factors influence attitudes to the congestion charges. The dependent variable is the response to the voting question described in section 4, where respondents were asked how they would vote in a referendum about the congestion charges and the associated infrastructure package. Answers were indicated on a 5-grade scale, from "Definitely yes" to "Definitely no", so ordered logit models are used. The models were estimated with Biogeme (Bierlaire, 2003, 2008). The independent variables are socioeconomic variables, attitude factors, variables related to self-interest, and belief in positive and negative effects. Since the latter may be highly influenced by the independent variable, we also estimated models without the belief-in-effects variables. These models may in fact be preferable, due to the endogeneity concerns. However, testing whether changes in beliefs may have caused the change in attitudes is one of our main questions, and including beliefs in effects in the models allows us to test this. If the models indicate that changes in beliefs may have caused the attitude change, this would not be conclusive evidence, since the causality may run in the reverse direction; but if the models indicate that changes in beliefs have not contributed to the attitude 
changes, then we can conclusively reject the hypothesis that changes in beliefs have caused the attitude changes.

First, we test whether variables influence voting differently between the two years. The test is set up as follows. We estimate two year-specific models, one for the 2012 sample and one for the 2013 sample. The null hypothesis is that all independent variables have the same impact on the dependent variable for both years, i.e. the parameters in the two models are the same. If so, a model estimated on the pooled sample will have the same model fit as the two year-specific models. The hypothesis that the parameters in the two year-specific models are the same can hence be tested using the $\chi^{2}$ test of parameter restriction. The test of parameter restriction is performed both with and without including the beliefs-in-effects variables. The $\chi^{2}$ tests show that the hypothesis that the parameters are the same in the two years cannot be rejected in either of the model specifications. The only difference is a year-specific constant, indicating that overall support is higher in 2013 than in 2012. The year-specific constant turns out to be remarkably similar across different groups of respondents; differences are explored further below.

Estimation results are presented in

Table 5. 'Income' is a categorical variable with five levels, and is coded as a continuous variable using interval midpoints. 'Education' has four levels reflecting highest education (1=High school, $2=$ College, $3=$ =University education 1-3 years, 4=University education $>3$ years university), and is implemented as a piece-wise linear function with a kink at 2. High education, high income and being male all tend to increase support.

The variable 'Cars per household' has four levels $(0,1,2,>2$ cars in the household) and is implemented as a piece-wise linear function with a kink at 1 . 'Toll payments' is the approximate (expected ${ }^{6}$ ) number of trips across the cordon per month, coded on a 4 level scale: 0, 3, 10 and 20. It is implemented as a piece-wise variable with kinks at 10 and 3 trips/month. The results show that respondents' support for the charges decrease the more they pay, and the more cars they have in the household. Access to a company car increases support, which is logical since company cars are exempt from the charges 7. The value of travel time ranges from 0 to $18 € / \mathrm{h}$ on a seven level scale and is implemented as piece-wise linear variable with kinks as 3 and $15 € / \mathrm{h}$. The higher value of time respondents have, the more they support congestion pricing. In summary, respondents' self-interest apparently matters for their opinion about congestion charges.

Respondents' approximate number of transit and bicycle trip frequencies is coded as number of trips per month on a 4 level scale, 20, 10, 3 and 0 . Both variables influence their attitudes about congestion charges. Note that the models already control for toll payments and car ownership. Presumably, high transit and transit frequencies indicate that respondents have access to good non-car alternatives.

Turning to the attitude factors, high indices on PRICE (accepting pricing policies in general) and ENV (environmental concerns, support for traffic restraint, equity concerns) tend to increase support for the charges, as expected. A high index on CAR (taxes in general and on cars in particular are too high, traffic is not a big environmental problem) has a strong negative effect on the attitude to the charges, also

\footnotetext{
${ }^{6}$ In the 2012 survey

${ }^{7}$ According to Swedish tax rules, the costs for congestion charges are included in the generic tax that workers pay for the benefit of having access to a company car.
} 
as expected. The index of the fourth factor, EQUI (equity concerns, positive view of governmental allocation), does not significantly influence the attitude to the charges.

Finally, beliefs in positive and negative effects, respectively, tend to influence attitude to the charges in the expected directions. Two of the beliefs factors, increased transit crowding and decreased traffic, were not significant. As pointed out earlier, the causality between these beliefs and the attitude towards the charges most likely runs in both directions, so there is clearly a risk for endogeneity here. Fortunately, reestimating the model without the belief variables (Model 2) does not change the other parameters to any large extent.

Table 5. Estimation results - Determinants of stated voting intention in a referendum about congestion charges and the associated infrastructure package.

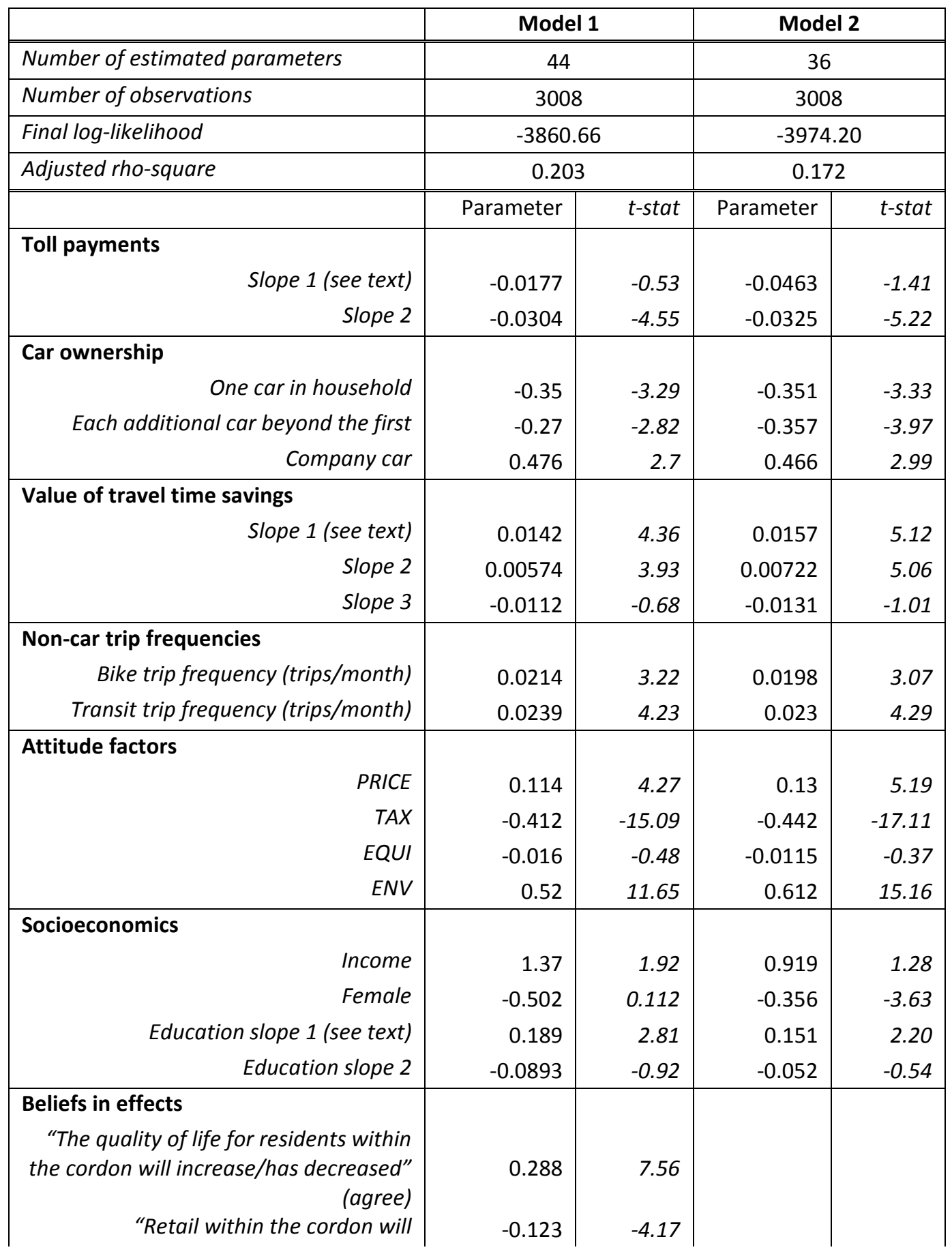




\begin{tabular}{|c|c|c|c|c|}
\hline $\begin{array}{r}\text { decrease/has decreased" (agree) } \\
\text { "Time spent in car queues will } \\
\text { decrease/has decreased" (agree) } \\
\text { "I am generally satisfied with the public } \\
\text { transport" (agree) }\end{array}$ & 0.105 & 5.01 & & \\
\hline \multicolumn{5}{|l|}{ Year-specific constants } \\
\hline Male 2013 & 0.168 & -1.49 & 0.158 & 1.50 \\
\hline Female 2013 & 0.961 & 8.55 & 1.02 & 9.82 \\
\hline 2 cars in household 2013 & 0.419 & 2.42 & 0.449 & 2.64 \\
\hline \multicolumn{5}{|l|}{ General model parameters } \\
\hline Constant & 3.82 & 4.36 & 1.63 & 1.96 \\
\hline tau1 & 0 (fixed) & - & 0 (fixed) & - \\
\hline $\operatorname{tau} 2$ & 1.39 & 27.95 & 1.32 & 27.95 \\
\hline tau3 & 2.29 & 37.59 & 2.18 & 37.45 \\
\hline tau4 & 4.02 & 47.44 & 3.83 & 47.13 \\
\hline
\end{tabular}

We can hence conclude that respondents' stated voting in a congestion pricing referendum is influenced both by self-interest - measured by variables such as toll payments, value of time and car ownership - and their attitudes to associated issues, such as equity, environment, taxation and trust in the government. In fact, these related attitudes seem to be even more important than self-interest. Self-interest variables alone can only explain $21 \%$ of the total explanatory power of the full model (measured by increase in log-likelihood over a model with only constants), and socio-economic variables as little as $0.2 \%$, while attitudes explain $79 \%$.

As mentioned above, the $\chi^{2}$ tests indicate that we cannot reject the hypothesis that the parameters are the same in the two years; the only difference is the year-specific constant. We also tested specifically whether the parameters for the four attitude factors were different between the years (keeping the rest of the parameters constant across years), and again we could not reject the hypothesis that the parameters were the same in the two years. Hence, the ways in which various variables influence voting attitudes to congestion charges seem to have remained constant. This means that we can reject the reframing hypothesis (5) above.

Since the year-specific constant is significant, we can also conclude that the entire change in attitudes between the years cannot be explained solely by changes in the variables, neither by changes in attitudes or beliefs, nor in any other variables. This implies that at least part of the change must be attributed to loss aversion (6) or status quo bias (7).

Testing year-specific constants for various socioeconomic groups reveals that they are remarkably similar across groups, almost regardless of socioeconomic characteristics travel behaviour and toll payments. Only two differences between groups turn out to be significant: women change their attitude more than men, and men in households with two or more cars change more relative to other groups.

\subsection{Factors contributing to attitude changes}

Using Model 1 above, we can calculate the approximate contributions from changes in different variables to the total attitude change in the following way. We take the population averages of all variables in the 2012 sample, and calculate the average latent variable for 2012, $u_{2012}$. Then, we calculate the corresponding population 
averages of all variables in the 2013 sample, and calculate the average latent variable for 2013, $u_{2013}$ (including the year-specific constant, which captures the "unexplained" change in attitudes). The difference $u_{2013}-u_{2012}$ is a measure of the total attitude change in the population, and we normalize this difference to $100 \%$. To estimate the contribution from each type of variable, we replace the 2012 population averages with the 2013 population averages for one group of variables at a time. This enables us to compare the contribution from each group of variables to the total change in attitudes. The result is illustrated in Figure 6.

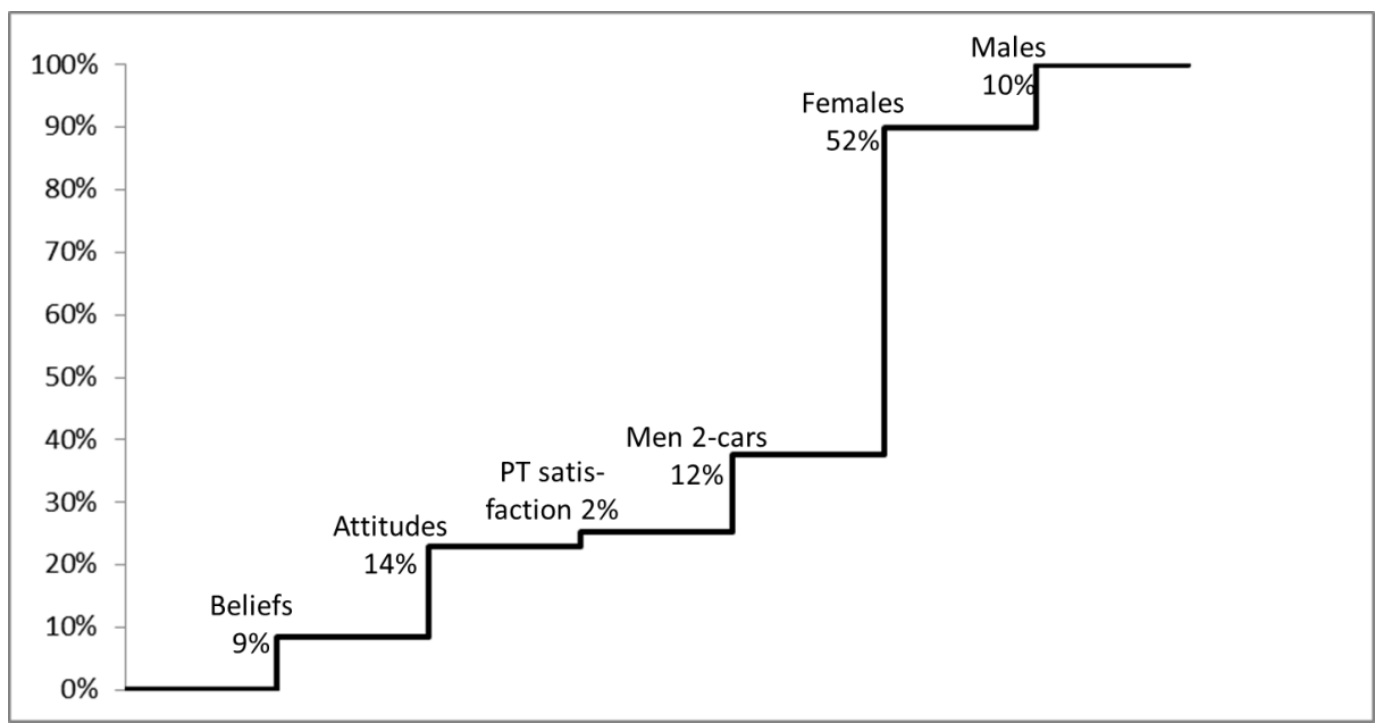

Figure 6. Contribution to total attitude change from changes in different variables.

Changes in beliefs contribute with $9 \%$ of the total change in attitude to the charges. As shown earlier, this is only an effect of less beliefs in negative effects. The direction of the causality here is doubtful, as discussed earlier. In any case, we can conclude that this effect is small, so changes in beliefs can certainly not be the main driver of the changed attitudes to charges, refuting hypothesis (2) at least to a large extent (hypothesis (1) has already ben refuted since there was no increase in beliefs in positive effects).

Changes in related attitudes contribute with $14 \%$ of the changed attitude to the charges. This lends some support to hypothesis (4) above, that changes in related attitudes may cause a second-order effect on the attitude to the charges. As shown earlier, the main attitude differences between the years are increased concerns for equity in society and reduced concerns for high taxes and costs of car use and ownership (see t-tests in table 4). As was also pointed out earlier, these attitude changes are not necessarily caused by the introduction of the charges or the surrounding debate and political campaigns. During the period between the two surveys, the left/green political block increased its voter support, and this is certainly consistent with the shift in political attitudes seen here. Hence, it seems likely that some of the shift in attitudes seen in our survey is an unrelated trend that just happens to increase support for the charges, rather than being directly caused by the introduction of the charges. That more respondents now view pricing a ferry as a fair allocation mechanism may be due to the introduction of the charges, however.

Increased satisfaction with the public transport system stands for a minute $2 \%$ of the overall attitude change. This is in the expected direction, so it lends some support to hypothesis (3), that a clear use of revenues will increase the support. However, the effect is almost negligible in this case. 
The absolute majority of the change, however, remains unexplained and is captured in the year-specific constant. Over three quarters (75\%) of the increased support for the charges can only be attributed to status quo bias (7); it is unexplained by any other variable. It is remarkably similar across socioeconomic groups and with respect to travel characteristics. Only three distinct patterns can be found: the effect is songer for women than for men, and stronger for men who belong to households with two cars or more than for other groups. Had loss aversion (6) been the explanation, toll payments should have had a less negative influence in the second year than in the first, or there should have been a larger attitude change among frequent drivers compared to nondrivers.

Status quo bias can also be caused by cognitive dissonance, i.e. accepting unavoidable or irreversible changes (as shown in a nice experiment by Schade and Baum (2007)). However, this seems to be unlikely in this case, since the political debate about the charges and the associated infrastructure package was extremely lively at the time of the surveys. The impression was certainly not that the outcome was inevitable; in fact, a referendum about the charges is scheduled for the autumn of 2014, a year after our second survey.

So, we can only conclude that the absolute majority of the change is caused by a general, overall increased support for the charges, largely similar across most groups, although stronger for females and men in two-car households.

\section{CONCLUSIONS}

Virtually all cities that have introduced congestion charges have seen public opinion become more positive after the introduction. Gothenburg is the latest example in this series. We find that the share of respondents who would "definitely" or "likely" vote yes in a referendum about the charges and the associated infrastructure package funded by the revenues increased from 33\% right before the introduction to $50 \%$ a year later (excluding "don't know" responses). The share of positive respondents stating that they "definitely" would vote yes increased from a third to almost a half.

Several explanations of this phenomenon have been put forward in previous literature. The explanations are not mutually exclusive; they may all contribute to some extent to the change in attitudes. Using surveys before and after the introduction, we have tested how much the various explanations contribute to the change.

The most commonly proposed explanation is that positive effects turn out to be larger than expected. Our results do not support this at all in Gothenburg; in fact, beliefs in positive effects actually decreased after the introduction. Beliefs in negative effects also decreased, on the other hand; the perception that things did not turn out as bad as expected may have contributed somewhat to the more positive attitudes. If we ignore reverse causality (that more positive attitudes may reduce beliefs in negative effects, rather than the other way around), decreased beliefs can have contributed with up to $9 \%$ of the total change in attitudes. Since there almost certainly is some degree of reverse causality, the real number is most likely lower than this.

Several improvements in the public transport system were made shortly before the introduction of the charges. They were partly funded by the revenues from the charges, and were marketed as a part of the general charge/infrastructure package. This 
hypothecation of charge revenues may have increased support for the charges. However, our analyses suggest that this contribution is almost negligible at $2 \%$.

The process of introducing congestion charges and the associated debate and political campaigns may change related attitudes, for examples regarding equity, environment or towards pricing policies in general. For example, it has been suggested that a contributing factor to the increased support for the Stockholm charges was an increased acceptance of pricing as a method for allocating scarce resources and regulating externalities. Our results lend some support to this; changes in related issues contribute with around $11 \%$ of the total change in attitude towards the charges. However, this change in related attitudes is not necessary caused by the introduction of the charges - it might simply be a part of longer trend in favour of the left/green political block, and this just happens to work in favour of the charges.

There may also be changes in what other attitudes influence the attitude towards the charges. A political debate or campaign charges can cause a reframing of the congestion charges, where the charges can be reinterpreted or "re-branded" from, say, a fiscal measure to an environmental measure. In the longer perspective, this is most likely an important mechanism, but there is no evidence of this in our results, which only encompass one year. All variables, including attitude factors, seem to influence the attitude towards the charges in exactly the same way before and after the introduction.

The final explanation is status quo bias, and this seems to be by far the most important mechanism, contributing with three quarters of the total change in attitudes. Interestingly, the change is stronger among women. The status quo bias does not seem to be caused by loss aversion; if it was, we would for example have seen a smaller attitude change among respondents who pay little or nothing compared to those how pay a lot. Instead, we see a similar change in attitudes across almost all groups, be it car drivers, environmentalists or transit users, irrespective of self-interest and general attitudes - the only distinction is that the effect is slightly stronger among men in twocar households. Hence, the status quo bias seems to be a general phenomenon: the change is resisted partly just because it is a change, and once the policy is there, the support increases partly just because "it's there". The existence of status quo bias poses a philosophical problem for democracies and welfare evaluation. If a population would vote against a policy before it is introduced, but would vote in favor of keeping it once it has been introduced, and the only reason for the change in attitudes is status quo bias is it then democratically defensible to introduce the policy? One way to come to grips with this question is to say that it has to do with the characteristic of the policy: if it in some way means that resources are spent more efficiently, and if reasonable measures of public welfare increase, then one is tempted to answer yes. But this is far from an obvious answer; the question goes well beyond the scope of this paper.

We can only speculate regarding whether our results are applicable to other cities as well. Clearly, the visible congestion reductions in London and Stockholm were both larger and less expected, so the "larger effects than expected" may be a bigger factor in those cities than in Gothenburg. However, Eliasson (2014) shows that this can only explain a minor part of the attitude change in Stockholm. As to the Norwegian systems, there were very little traffic effects to speak of, and the benefits of revenue spending were not visible until well after the change in public attitudes were already visible. It is clear that the framing of congestion pricing - for example, whether it is presented as a fiscal, environmental or traffic-technical measure - plays a substantial role for public acceptability (Eliasson \& Jonsson, 2011; Hamilton \& Eliasson, 2012; Schade \& Schlag, 2003). In the longer run, how congestion pricing is framed is most likely a decisive factor. However, reframing seems to be a too slow process to affect attitudes to 
congestion pricing in the short run studied here, and hence it seems unlikely that this is the main driving factor behind the considerable attitude change before/after introduction that many cities have experienced. Given this, we are inclined to believe that status quo bias has played a major role for the change in public attitudes to congestion pricing in other cities as well.

\section{ACKNOWLEDGMENTS}

The survey in this study used is adapted from a questionnaire developed by Carl Hamilton, Jonas Eliasson, Karin Brundell-Freij, Kati Kiskilää, Charles Raux, Stephanie Souche and Juha Tervonen, funded by the ERA-NET programme SURPRICE . We are grateful to Per Näsman for help with the factor analysis.

\section{REFERENCES}

Anas, A., \& Lindsey, R. (2011). Reducing Urban Road Transportation Externalities: Road Pricing in Theory and in Practice. Review of Environmental Economics and Policy, 5(1), 66-88.

Bierlaire, M. (2003). BIOGEME: A free package for the estimation of discrete choice models. Proceedings of the 3rd Swiss Transportation Research Conference, Ascona, Switzerland.

Bierlaire, M. (2008). An introduction to BIOGEME Version 1.6, biogeme.epfl.ch.

Börjesson, M., \& Eliasson, J. (2014). Experiences from the Swedish Value of Time study. Transportation Research A, 59, 144-158.

Börjesson, M., Eliasson, J., Hugosson, M. B., \& Brundell-Freij, K. (2012). The Stockholm congestion charges - 5 years on. Effects, acceptability and lessons learnt. Transport Policy, 20, 1-12.

Brundell-Freij, K., Jonsson, L., \& Källström, J. (2009). Accepting charging - a matter of trusting the effects? Proceedings of the European Transport Conference.

Eliasson, J. (2008). Lessons from the Stockholm congestion charging trial. Transport Policy, Transport Policy, 15(6), 395-404.

Eliasson, J. (2014). The role of attitude structures, direct experience and framing for successful congestion pricing. Transportation Research A, 67, 81-95. 
Eliasson, J., \& Jonsson, L. (2011). The unexpected "yes": Explanatory factors behind the positive attitudes to congestion charges in Stockholm. Transport Policy, 18(4), 636-647.

Frey, B. S. (2003). Why Are Efficient Transport Policy Instruments so Seldom Used? In J. Schade \& B. Schlag (Eds.), Acceptability of Transport Pricing Strategies. Elsevier, Oxford.

Goodwin, P. (2006). The gestation process for road pricing schemes. Local Transport Today, 444.

Gopinath Menon, A. P., \& Kian-Keong, C. (2004). ERP in Singapore - What's been learnt from five years of operation? Traffic Engineering \& Control, 45(2).

Hamilton, C. J., \& Eliasson, J. (2012). Decisive factors for the acceptability of congestion pricing. In C. J. Hamilton (Ed.), Implementing Road Pricing: Standards, Institutions, Costs, and Public Acceptance, Doctoral dissertation. Centre for Transport Studies, KTH Royal Institute of Technology.

Hamilton, C. J., Eliasson, J., Brundell-Freij, K., Raux, C., \& Souche, S. (2014). Determinants of congestion pricing acceptability ( No. 2014:11). CTS Working Paper. Centre for Transport Studies, KTH Royal Institute of Technology.

Heberlein, T. (2012). Navigating environmental attitudes. New York: Oxford University Press.

Henriksson, G. (2009). What did the Stockholm Trial mean for Stockholmers? Gullberg and Isaksson (eds.): Congestion taxes in city traffic. Lessons learnt from the Stockholm Trial. Nordic Academic Press.

Jones, P. (1991). Gaining public support for road pricing through a package approach. Traffic Engineering and Control, 32(4), 194.

Kahneman, D. (2011). Thinking, Fast and Slow. Farrar, Straus and Giroux. 
Ozer, G., Beria, P., \& Pacchi, C. (2012). Do you accept MI? Acceptability of Milan's congestion charging in the light of London and Stockholm. (Masters thesis). Politecnico di Milano, Milan.

Raux, C., \& Souche, S. (2004). The Acceptability of Urban Road Pricing: A Theoretical Analysis Applied to Experience in Lyon. Journal of Transport Economics and Policy, 38(2), 191-215.

Schade, J., \& Baum, M. (2007). Reactance or acceptance? Reactions towards the introduction of road pricing. Transportation Research Part A: Policy and Practice, 41(1), 41-48.

Schade, J., \& Schlag, B. (2003). Acceptability of urban transport pricing strategies. Transportation Research Part F: Traffic Psychology and Behaviour, 6(1), 45-61.

Souche, S., Raux, C., Eliasson, J., Hamilton, C. J., Brundell-Freij, K., Kiiskilä, K., \& Tervonen, J. (2014). Predicting the results of a referendum on urban road pricing in France: The cry of Cassandra? TRB Proceedings.

Tretvik, T. (2003). Urban road pricing in Norway: public acceptability and travel behaviour. In J. Schade \& B. Schlag (Eds.), Acceptability of Transport Pricing Strategies. Elsevier, Oxford.

Zmud, J. (2008). The public supports pricing if... A synthesis of public opinion studies on tolling and road pricing. Tollways, (Winter), 29-39. 